\title{
Blanchot ferido com fogo
}

Daniel de Oliveira Gomes

Unicentro PR

\section{Resumo}

O presente ensaio trabalha especificamente com a obra de um autor da filosofia e da literatura francesa pós-estruturalista, Maurice Blanchot. $O$ artigo visa produzir uma confabulação blanchotiana com a questão fascinante da fala, da literatura e dos sentidos do próprio autor, confessando um desespero e uma contaminação ardente e inevitável. Aproximando-o dos paradoxos do espaço literário, queremos demonstrar metodologicamente o hermetismo do autor e o modo com o qual ele sempre colocou a filosofia contra a própria filosofia. Até que ponto Blanchot veste uma infantilidade kafkiana em seu aberto compromisso com a escritura? Ler Blanchot só pode-se fazer ao gesto de um ferimento com fogo, a perda de memória que se sente ante a ameaça de um revolver carregado. Disto, trata-se 0 artigo.

Palavras-chave: Blanchot, memória, Kafka, filosofia

\begin{abstract}
This essay deals specifically with Maurice Blanchot's philosophic and literary work. It aims to raise such a blachotianian confabulation into its fascinant question of word, literature and their meanings for Blanchot himself, avowing some flaming and unavoidable despair and contamination. At approaching Blanchot from these literary space paradoxes, we want to demonstrate methodologically the author's and the way by which he always has put philosophy against itself. We ask: At what point does Blanchot wears a kafkian infantility in his open commitment towards writing? So reading Blanchot is only possible with a sign like a firehurting, the loss of memory that one can feel under a gun pointed to his head.
\end{abstract}

Keywords: Blanchot, memory, Kafka, philosophy

\section{Por falar em Blanchot}

Falar de Blanchot é falar "em" Blanchot". Estar em Blanchot é compartilhar sua fala infinita. Falar de Blanchot é como ter um ovo nas mãos. Ferimento com fogo, ficção.

\footnotetext{
${ }^{6} \mathrm{O}$ presente estudo é resultado de minhas pesquisas, sobre o filósofo Maurice Blanchot, junto à Universidade de Brasilia (UNB), onde pertenço como pesquisador voluntário ao "Núcleo de Estudos Blanchotianos e do Pensamento do Fora". Este núcleo - sediado no "Departamento de Línguas Estrangeiras e Tradução", liderado pelos professores Dr. Eclair Antonio Almeida Filho e Dr. Eduardo Aníbal Pellejero - tem, como objetivo, tanto estudar a obra ficcional e a obra literária do autor e escritor francês, quanto divulgar no Brasil e traduzir suas obras para o português. A linha a que pertence o trabalho é "A discussão blanchotiana da narrativa". A primeira questão que (re)cai esta investigação é, por assim dizer, metalinguística, ou seja, questionar a própria fala crítica como possibilidade indefinida de uma verdadeira fala "de" Blanchot. Afinal, só é possível falar de Blanchot falando "em" Blanchot. Quer seja, compartilhando suas indagaçð̄es como flutuaçðes reticentes de um espírito questionador ad infinitum, um notável e complexo savoir-faire, que nos move, nos comove, em direção ao próprio desespero da dúvida. Circularidade onde achar não é propriamente encontrar o real, mas continuar circulando.
} 
Para compreender esta brincadeira com fogo, no duplo sentido, de um fogo pacífico e belicoso que é o ato escritural de Blanchot, gostaria de entregar-me um pouco ao seu "fascínio da ausência de tempo", ou seja, sem querer afirmar ou negar um rosto adulto, mas apenas deixando hoje que minha infância me abisme através da sobrevivência de Blanchot, neste ensaio. Assim, vou escrevendo um pequeno memorial caloroso, ou melhor, um pequeno fragmento de diário, que jamais será lido por mim, como que lançado ao fogo, feito para desaparecer, ao sabor de "chamas imaginárias" (termo de Bataille).

Quero escrever como devir, no reino da indecisão do suave começo, tal como Simone Curi apontou em Clarice Lispector ao descrever a imagem do ovo: "o ovo é devir (...), a escrita é devir (...)" (CURI, 2001, p. 149).

Blanchot infantil. Penso-o como uma criança apaixonada com um lança-chamas nas mãos. Vejo-o como um "infante". Super-homem, bélico, e, ao mesmo tempo, pequeno, quebradiço ovo... No entanto, não no sentido baudelairiano de flanêur, um mero observante do seu tempo, de uma moda de filosofia pós-estrutural, ovo depositado de anômalos literatos do vazio, Mallarmé, Valéry, Joyce, Joubert ou Proust. Vejo-o "infante", no sentido que Agamben associa $a$ infância à experiência.

Como infância do homem, a experiência é a simples diferença entre humano $e$ linguístico. Que o homem não seja sempre já falante, que ele tenha sido e seja ainda in-fante, isto é a experiência. (AGAMBEN, 2005, p.62).

Por vezes, este lança-chamas serve para "apagar" toda uma biblioteca anterior a ele mesmo. Somente um espírito ardentemente infantil poderia ter feito o que Blanchot fez, brincando sobre seu tempo, que é o mesmo feitio de Kafka. Ambos compartilham uma intimidade dilacerante, o mesmo ninho.

\section{I Blanchot brincando com fogo}

E assim se faz, coisa possível apenas na execução de um canto, uma dança nietzschiana, mesmo que devotadamente desqualificado de tudo que já se fez, qual o personagem protagonista de Truffaut, no filme "Fahrenheit 451". Uma estranha paixão exaltada e desesperadamente nova e violenta. Blanchot é um infante, em desespero infantil, como Montag.

Ou quem sabe, por vezes, como a personagem vizinha de Montag, Senhora Blake, aquela que se ajoelhou entre os livros, de títulos dourados, encharcados de querosene no chão e acusou Montag com o olhar. Senhora Blake, como uma garotinha indefesa ante o fogo, tinha visto bombearem o líquido que traziam em tanques de número 451 presos aos ombros, tal como Blanchot nos coloca na exata posição de desconfiança epistêmica de Montag. De algum modo, precisamos entender esta pessoa, este autor, esta senhora apaixonada que se sente pela ferida das coisas, dos livros que não podem chorar, pois...

Não se feria ninguém, apenas coisas! $\mathrm{E}$ uma vez que as coisas não sentiam nada, $\mathrm{e}$ coisas não gritam nem choram, como esta mulher poderia começar a gritar e a 
chorar, não havia nada para importunar sua consciência depois. Você está simplesmente limpando. Basicamente, um trabalho de faxina. Tudo em seu devido lugar. Rápido com a querosene! Quem está com os fósforos? (BRADBURY, 2009, p.59).

Blanchot não precisa que se escreva sobre ele. Se quisermos consumi-lo, atear-lhe fogo, em seus dedos já se encontrará girando com certo deboche um palito de fósforos. Eis esta loucura entre o fogo e os livros, a Babel blanchotiana a qual precisamos queimar criticamente, a valiosa biblioteca que precisamos consumir, o acervo infinito, de alguém ao lado. É quando surpreendentemente a pessoa mesma nos mostra que não precisa de nós, de nada, de ninguém além dos livros; ela mostra um acendedor, um simples fósforo de cozinha...

Abriu ligeiramente os dedos de uma mão e em sua palma estava um objeto fino. Um fósforo comum de cozinha. À vista dele os homens se precipitaram a sair e se afastar para longe da casa. O capitão Beatty, mantendo a dignidade recuou lentamente pela porta da frente, o rosto corado, queimado e reluzente após mil incêndios e emoções noturnas. Meu Deus, pensou Montag, é isso mesmo! O alarme sempre chega à noite. Nunca de dia! Será porque à noite o fogo é mais bonito? Mais espetacular, um programa melhor? A face rosada de Beatty à porta agora traía um princípio de pânico. A mulher girava nos dedos o palito de fósforo. Os vapores de querosene exalavam ao seu redor. Montag sentiu o livro escondido pulsar como um coração contra seu peito./ - Vá - Disse a mulher, e Montag se sentiu recuando cada vez mais para fora da porta, depois de Beatty, descendo os degraus, atravessando o gramado onde o rastro de querosene se estendia como a baba de uma lesma maligna. / Na varanda da frente, para onde viera avaliá-los calmamente com os olhos, a mulher parou imóvel; sua impassividade, uma condenação. (BRADBURY, 2009, p.63).

E, como diria Flaubert, o fogo purifica tudo... "Ao ouvir-se gritar 'fogo!' deve começar-se por se perder a cabeça." (FLAUBERT, 1974, p.59).

\section{II. "Chocar" Blanchot com Kafka}

Como falar de um autor como Blanchot sem perder a cabeça, sem cair em desespero? O desespero como "doença mortal", visto que se não nos aparentamos desesperados, isto pode justamente significar que estamos em estado de desespero, dizia Kierkegard. Como falar desesperadamente de Blanchot, sem sobrevir na loucura e no desastre da filosofia contra a própria filosofia, tal como Blanchot afirmava a potência literária de Kafka contra a literatura?

Em "A escritura do Desastre" podemos ler: 
Quando Kafka deixa entender a um amigo que ele escreve porque, de outra forma, tornar-se-ia louco, ele sabe que escrever é já loucura, é a sua loucura, espécie de vigília fora de consciência, insônia. Loucura contra loucura?

E há uma glória motriz neste desespero que presume o universo kafkiano. Blanchot disse "alguém põe-se a escrever, determinado pelo desespero. Mas o desespero nada pode determinar" (BLANCHOT, 1987, p.50). Acredito que a única fidelidade (infiel) possível sobre seu legado está em visualizá-lo, desesperadamente, como um guerreiro, uma criança.

Uma vez Georges Bataille perguntou se era "preciso queimar Kafka" (BATAILLE, 1989, p.129). Porque ele vislumbrava Kafka como um grande exemplo, porém, de modo muito provocativo, celebrando seu mestre, mas excitado e um tanto profanador. No caso-Blanchot, o perigo não está em perguntar o mesmo, e sim se seríamos antes qual Max Brod, um amigo cheio de escrúpulos, pronto para salvá-lo do sacrifício. Mas, assim mesmo, lancemos a mesma pergunta - a de Bataille sobre Kafka - contra Blanchot.

Pergunto-me se a impossibilidade de entender o ovo condiz com a impossibilidade autoral de ler a obra, conforme Blanchot... Sinto apenas sua superfície, na descrição de João Cabral de Melo Neto, "a reserva que um ovo inspira (...) é a que se sente ante um revólver, e não se sente ante uma bala" (CABRAL DE MELO NETO, 1995). O revólver e o ovo, a violência obscura da arma de fogo e a delicadeza mais "clara" do ovo, o infante soldado e o infante menino que parasita meus mestres...

$O$ fascínio ameaçante que me afirma que devo recordar-me dignamente de minhas leituras de Blanchot, agir como a galinha: devo "chocar" responsavelmente interpretaçz̃es blanchotianas no meu ninho de leituras, que me relembra algo no interminável silêncio de signos supernutritivos, sob o reino do fascínio.

É, também, o reino do ovo lido por Clarice Lispector: "como o mundo, o ovo é obvio". Podemos afirmar, certamente, que a obviedade não é a característica maior da estilística de Blanchot, seja no campo da fiç̧ão ou da filosofia, porém, é sempre um texto poético, circular, e, para mim, oval.

\section{Decifrar Blanchot: queimá-lo}

Octávio Paz considerava o conceito de poesia como uma salvação e um abandono, uma oração e uma litania, ao mesmo tempo, poesia como um elemento distintivo no interior de uma obra que tem por função distingui-la de um utensílio, ou seja, fora de um esquema de superação (técnica). Blanchot, realmente, não tem fim. Não há começo.

No conceito de útil operado por Bataille, Blanchot não ingressaria no mundo luminoso das significaçðes, da utilidade, mesmo que filosófica. Ele deve ser encarado antes como um profundo (e sempre superficial) poeta... Barthes nos explicou, algumas vezes, que o poeta clássico era o poeta que vivia o tempo da "arte de expressão" sobre o pensar, enquanto que o poeta moderno já se depara no tempo onde a sua realização não é mais uma obra imagética como um ornamento da prosa, e sim instalar o pensamento como efeito do discurso. Blanchot,

\footnotetext{
${ }^{7}$ Tradução não publicada cedida, informalmente, pelo prof. Dr. Eclair Antônio Almeida Filho (UNB).
} 
por sua vez, estaria no tempo do fascínio imperfeito da infância. O fascínio, por exemplo, da ausência de tempo, da ausência de obra. Por isso falar de Blanchot é queimá-lo, ausentar-se pela alocução.

Entre o ovo e o revólver: ali vislumbro as chamas do infante. Em termos blanchotianos, a visão do escritor é a visão quase plena do fascínio, ou melhor, a visão do encantamento infantil - ovalado, ovulado - o momento em que tudo germina incessantemente. Por este motivo, o escritor não vai rumo a uma superação, uma segurança, a macro-percepção, a linguagem para todos.

Quando o faz, apenas redescobre a ambigüidade da solidão interminável em que já não é o "eu" mesmo. Já Barthes, com seu revolver, está preocupado em afirmar a morte do autor, a mesma arma com a qual Nietzsche assassinou a Deus, e que Foucault assassinou o sujeito histórico tradicional. Barthes é um grito, Foucault é uma voz, já Blanchot é um silêncio.

\section{Blanchot e a terapia do branco}

Se pegássemos todos os coloridos amigos intelectuais, poetas, escritores, de Blanchot, e girásemos uns com os outros, teríamos o tom branco blanchotiano. Mas nesta roda de amigos, onde devemos incluir Kafka, ocorre um pacto escritural terapêutico, onde estranhamente as feridas são drenadas e ao mesmo tempo aprofundadas, como dirá Tina de Alarcón no prefacio español de "El Processo".

Y el gozo fue la trampa en que cayó Kafka, de forma tan irremediable que cuando quiso salir no pudo de ninguna manera (...) En realidad - esa era la trampa -, la escritura no curaba su herida, la drenaba momentáneamente y, al mismo tiempo, la profundizaba. (ALARCÓN, 1999, p.7.)

Uma escritura terapeuticamente lançada, arremeçada, contra si mesma, gozada e angustiante, como uma bala disparada no duelo das armas de Kafka e Blanchot.

Em Blanchot, o escritor, sempre ferido com fogo, tem em mãos a terapia da página branca, o sério branco gozado, o branco brando do apagamento, branco (insemina)dor, a superficie profunda do branco.

Quando não estou escrevendo, eu simplesmente não sei como se escreve. E se não soasse infantil e falsa a pergunta das mais sinceras, eu escolheria um amigo escritor e lhe perguntaria: como é que se escreve?/ Porque, realmente, como é que se escreve? que é que se diz? e como dizer? e como é que se começa? e que é que se faz com o papel em branco nos defrontando tranquilo? (LISPECTOR, 1999, p. 156. Grifos nossos)

O branco de um ovo delicadamente aninhado nas mãos (especificamente a mão esquerda, a mão responsável pela pausa, como nos ensina com a metáfora da "preensão persecutória", em "O espaço Literário"). O branco em questão é, igualmente, a perda de memória que se sente ante a ameaça de um revolver carregado. 
Baudelaire discorreu, uma vez, que os soldados, com suas armas, seriam tão ingênuos quanto às crianças. Ter uma arma de fogo nas mãos é, deveras, uma brincadeira com a morte. Em termos kafkianos: "Écrire pour pouvoir mourir - Mourir pour pouvoir écrire", ou, como dirá Blanchot, em De Kafka à Kafka: "cela signifie que l'oeuvre est elle-même une expérience de la mort..." ${ }^{\prime}$. Por sua vez, as verdadeiras diversð̃es infantis são sempre violentas, como sabemos. Lançar ovos, por exemplo, é uma brincadeira muito infantil. Entretanto, o branco de Blanchot é antes uma eterna ameaça estática à frieza do olhar. Clarice diz que o ovo "é como um projétil parado no ar". (LISPECTOR, 1999, p.207). Acredito que o ovo em Clarice é a solidão essencial da obra.

\section{Blanchot anônimo}

E o que mobiliza Kafka, em seu diário, senão toda uma infantaria contra o pai, senhor Hermann, sua torre de babel, para lançar-lhe brilhantes ovos podres? Bataille descreve a obra de Kafka como uma obra que "testemunha em seu conjunto uma atitude absolutamente infantil" (BATAILLE, 1989, p.132), e assim o faz, posto que, do mesmo modo, Blanchot descreve Kafka como um jovem que simula a solidão essencial de todo escritor.

Kafka assemelha-se então a todo jovem em que desperta o gosto de escrever, que reconhece estar aí a sua vocação, que reconhece as exigências nela implícitas e não tem qualquer prova que esteja à altura de satisfazê-las. (BLANCHOT, 1981, p.52).

O gosto em escrever de Blanchot é, certa medida, o gosto kafkiano, quer seja, gosto neutro, gozo neutro, bel-prazer da palavra inconfessavelmente arremessada ao inacessível. Como diz Peter Pál Pelbart, "Blanchot redescobre na literatura um espaço rarefeito que se pð̃e em xeque a soberania do sujeito. O que fala no escritor é que 'ele não é mais ele mesmo, já não é ninguém': não o universal, mas o anônimo, o neutro, o fora." (Pelbart, 2002, p.290).

\section{Como Blanchot desnudaria Foucault}

Considero interessante, por exemplo, como Blanchot, que inicia o texto "Foucault tal como imagino" afirmando cabalmente nunca ter tido relações pessoais com Foucault, para escrever sobre ele, para "imaginá-lo", buscará uma fala tão amiga, que ressoa até mesmo como um eco de uma perdida voz foucaultiana. Uma voz irrepreensível, incessante, como se este fosse, por sua vez, o seu profeta que o desnudaria.

Mas esta é a relação, ad infinitum, com o Fora. O que faz o profeta é justamente isto: faz-nos sentirmos desnudados, na lembrança de uma vergonha original que nos assola inacreditavelmente e nos obriga a fechar os olhos, a nos tornarmos "cegos" e sábios como o profeta. O profeta contamina tudo com sua voz, na medida em que nos propõe o desnudamento

\footnotetext{
${ }^{8}$ BLANCHOT, Maurice, "La mort contente" in De Kafka à Kafka, Paris: Gallimard, 1981, p.137.
} 
de um rosto que só pode ser "absoluto de luz" (em Blanchot a metáfora da luz, não raro, tem o sentido do "fascínio inapreensível" e não o tom iluminista de verdade ou pureza, obviamente).

Ao mesmo tempo, ele jamais imita Foucault, é como se a fala de Foucault não pudesse ser vítima de mimeses, uma mera escolha estilística de palavras, figura simbólica ou alegórica, estilo autoral, mas sim uma linguagem que, fugindo a toda interpretação possível obsessivamente, não propriamente se rejeita ou assimila.

Logo, Blanchot é ele-mesmo e é ele-imprevisto, sua originalidade é assim, perdeu o silêncio, comunidade negativa onde "não há fim ali onde reina a finitude" (BLANCHOT, 1999, p.55), ou como diria Bataille, "comunidade dos que não tem comunidade" (Blanchot, 1999, p.65).

Foucault, por exemplo, é uma literatura em Blanchot (no dilema do olhar de Orfeu), quando, destinado a fazer-nos entender como entrar no templum, conforme na leitura de Barthes, estamos em uma região onde fatalmente queremos destruir o templo, sob "um rumor que muda de antemão tudo o que podemos dizer", como diz em O Livro Por vir.

\section{A comunidade ardente de Blanchot}

Ler Blanchot, para mim, é sempre uma calorosa experiência poética, exteriorização oval. É ingressar na comunidade dos que não tem comunidade, como diria Bataille. Comunidade negativa.

Gostaria de finalizar este texto, com as palavras de Clarice, visto que ela certamente pertence a essa comunidade inconfessável, e, estou certo, jamais incineraria, em sua biblioteca, um livro de Blanchot: "Por devoção ao ovo, eu o esqueci. Meu necessário esquecimento. Meu interesseiro esquecimento. Pois o ovo é um esquivo." (LISPECTOR, 1999, p.214.)

Seria preciso queimar Blanchot? Para destituí-lo da parte do fogo? Para nos contaminarmos com seu ardor? Acredito que podemos fazê-lo arder em sua sagacidade ao lê-lo como Kafka (certa relação do fogo que Blanchot lia em Hölderlin), ou seja, para portarmos também nosso próprio lança-chamas, agindo como Montag, contaminados por uma resistente potência e vontade de prolongamento do incessante.

Chamas que vão se intensificando, passando de objeto a objeto; ob-jectum, aquilo que é lançado de encontro... "a efervescência de todo o porvir na queimadura do instante." (BLANCHOT, 1999, p.34.)

Os livros bombardeavam seus ombros, braços, o rosto voltado para cima. Um livro pousou, quase obediente, como uma pomba branca, em suas mãos, as asas trêmulas. $\AA$ luz mortiça, oscilante, uma página pendeu aberta e era como uma pluma de neve, as palavras nela pintadas delicadamente. Em meio à correria e à fúria, Montag teve tempo apenas para ler uma linha, mas esta brilhou em sua mente durante o minuto seguinte, como se marcada a ferro em brasa. "O tempo adormeceu ao sol da tarde". Soltou o livro. Imediatamente, outro caiu em seus braços.- Montag, por aqui! (BRADBURY, 2009, p.60).

Para mim, ler Blanchot - em suma - é saber lidar com as labaredas. Enquanto muitos dançam e escorregam em interpretaçð̃es, visando abafar ou expandir o fogo, acredito que ter em mãos um livro de Blanchot é como quando se rouba um exemplar de senhora Blake... fascínio 
que nos alimenta na inocência, como "um passe de mágica", pensaria Montag. Pois é um dos infrequientes filósofos que não nos diz "por aqui!".

\section{Referências}

AGAMBEN, Giorgio. Infância e História. Destruição da experiência e origem da história, Belo Horizonte: UFMG, 2005.

ALARCÓN, Tina de, "En Torno a Kafka y su proceso" in KAFKA, Franz, El Proceso, trad. Tina de Alarcón, Madrid: Edimat Libros, 1999

BLANCHOT, Maurice. La bestia de Lascaux, El último em hablar, Barcelona: Tecnos, 1999. O Espaço Literário, Rio de Janeiro: Rocco, 1987.

De Kafka à Kafka, Paris: Gallimard, 1981

BATAILLE, Georges. É preciso queimar Kafka? In: A Literatura e o mal, Porto Alegre: L\&PM, 1989.

BRADBURY, Ray (2009), Farenheit 451, São Paulo: Editora Globo.

CURI, Simone. A escritura nômade em Clarice Lispector, Chapecó: Argos, 2001.

FLAUBERT, Gustave. "Fogo". In: Dicionário das idéias feitas, Lisboa: Ed. Estampa, 1974

KIERKEGAARD, Soren Aabye. "O desespero humano" in Os Pensadores, trad. Carlos Drifo, Maria José Marinho, Adolfo Casais Monteiro, São Paulo: Abril Cultural, 1979, p. 204.

LISPECTOR, Clarice. A descoberta do Mundo. Rio de janeiro: Rocco, 1999.

Daniel de Oliveira Gomes. Licenciado em Letras Vernáculas pela Universidade Estadual de Ponta Grossa - UEPG. Mestre (bolsista CAPES) e Doutor (bolsista CNPq) em Literatura pela Universidade Federal de Santa Catarina - UFSC. Estágio sanduiche de doutorado em Paris, sob vínculo institucional da Université de Lille III - UCGL (bolsista CAPES). Professor adjunto A na Universidade Estadual do Centro-Oeste - UNICENTRO - Paraná, onde auxiliou na implantação do "Mestrado em Letras". Membro fundador do Grupo de Estudos Blanchotianos e de Pensamento do Fora, junto à Universidade de Brasília - UNB (CNPq). Especula afinidades entre ficção e filosofia basicamente a partir de dois teóricos: Maurice Blanchot e Michel Foucault. Investiga, atualmente, a poesia portuguesa do presente, visando correlaçб̃es com a filosofia pós-estrutural francesa. 